\title{
Hypnotically induced boredom and time estimation'
}

\author{
P. James Geiwitz \\ UNIVERSITY OF MICHIGAN
}

\begin{abstract}
One of the primary obstacles to research on boredom and subjective time experience is seen to be the lack of techniques which permit quick, precise boredom manipulations. The use of posthypnotic cues for this purpose is suggested and performed on a single male subject. Four degrees of boredom triggered by cues in the waking state show a remarkably consistent and significant effect on production time estimates of five and ten seconds; the higher the boredom, the longer the subjective duration. The use of hypnosis for such research problems, i. e., the effect of subjective experiences on apparent duration, is advised.
\end{abstract}

\section{Problem}

A common introspective experience is the apparently slow passage of time associated with boredom. Psychologists, however, as Loehlin (1959) has pointed out, have had trouble substantiating this relationship, primarily because of methodological difficulties. Because variance of time estimates between subjects is great, most researchers prefer intra-individual comparisons. Because intra-individual comparisons are used, the intervals to be estimated are typically short, allowing more estimates per session. Because the intervals are short, experimental manipulation of boredom must be accomplished by methods that produce the phenomenon in two or more degrees precisely, quickly, and without carryover to the next interval. The lack of techniques fulfilling these requirements is one of the most imposing obstacles to the study of the boredom-time relationship.

The experiment to be discussed used hypnosis as the method of boredom manipulation. Under carefully specified conditions, posthypnotic cues can produce boredom in several precise degrees. Carry-over can be almost completely eliminated.

\section{Method}

The $\mathrm{S}$ was 20 years old, male, and a senior at the University of Michigan, majoring in business administration. He scored 11 on Form A of the Stanford Hypnotic Susceptibility Scale(Weitzenhoffer \& Hilgard, 1959), indicating a high degree of hypnotic susceptibility.

$\mathrm{S}$ was hypnotized and instructed to relive a classroom experience in which he had been "very, very bored." The boredom was dissociated from the particular situation and attached to a posthypnotic cue; $S$ was instructed, under hypnosis, to feel very, very bored whenever he saw the cue "B3." This procedure was repeated with other classroom situations that were "fairly" and "slightly" boring, to be attached to " $\mathrm{B} 2$ " and " $\mathrm{B} 1$, ," respectively. In addition, $\mathrm{S}$ was instructed to respond to " $\mathrm{O}$ " by feeling "not bored, not interested." Amnesia instructions removed conscious awareness of the significance of posthypnotic cues.

Cues were printed on $3 \times 5$ cards and placed in random order in front of S. At the command "turn" from E, S turned over the top card and began to experience the degree of boredom indicated. He had previously been instructed to then place the card face down in a box next to him, thereupon forgetting what was written on the card although continuing to experience the boredom until two time estimates had been completed.

One minute after turning over a card, S was asked to estimate five seconds and ten seconds by the method of production (Bindra \& Waksberg, 1956). E said, "Five (or ten) seconds, begin." When S thought the designated time had elapsed, he said, "Stop." He was told not to count to himself. The actual time between "begin" and "stop" was measured with a stop watch.

Four series of trials, three trials per condition per series, constituted the experiment. Each series was separated from the others by at least two days. An associate randomized each set of cues and noted the order for later recovery and analysis. In two sessions, the fivesecond estimates were taken first; in the others, the tensecond estimates. No order effects were found and the data are therefore considered without regard to order.

During the last two series, S's behavior in the minute preceding the estimates was observed through a oneway mirror and rated on a seven point scale running from "very withdrawn and weary" (1.0) to "fairly alert and responsive" (7.0). This was done to obtain independent validation of the effect of posthypnotic cues. Two raters were used, neither of whom knew the order of cue presentation. S did not know that he was being observed.

\section{Results}

Table 1 gives the behavioral ratings from the last two series. The results clearly indicate differences among

Table 1. Average Behavioral Ratings Associated with Degrees of Boredom

Series 3

Series 4

Cue Rater A Rater B Mean Rater A Rater B Mean

$\begin{array}{lllllll}\text { B3 } & 5.84 & 6.02 & 5.93 & 6.13 & 5.80 & 5.96 \\ \text { B2 } & 4.17 & 4.09 & 4.13 & 4.23 & 2.63 & 3.43 \\ \text { B1 } & 2.00 & 2.75 & 2.38 & 2.70 & 2.50 & 2.60 \\ 0 & 1.75 & 1.72 & 1.74 & 1.43 & 1.33 & 1.38\end{array}$

Note: Each entry under Rater A or B is the average of ratings on three trials with each cue. 
Table 2. The Effect of Boredom on Five Second Estimates

\begin{tabular}{cccccc} 
& \multicolumn{5}{c}{ Series } \\
Cue & I & II & III & IV & Mean \\
B3 & -1.54 & -1.24 & -1.09 & -1.24 & -1.28 \\
B2 & -0.44 & -0.36 & -0.36 & -0.32 & -0.37 \\
B1 & 0.49 & 0.51 & 0.55 & 0.26 & 0.45 \\
0 & 0.98 & 0.73 & 0.91 & 1.30 & 0.98
\end{tabular}

Note: Each entry under series is the average (in standard scores) of three trials.

the four degrees, providing verification of induced experience.

The data on time estimates among series showed considerable differences in elevation (mean estimate) and scatter (variance). Such differences did not seem to be related to boredom but rather to some arbitrary setting of the "internal clock." Raw scores were therefore converted to standard scores for analysis.

Table 2 gives the results for the five-second estimates, Table 3 for the ten-second estimates. The four series, in both cases, are alike in showing a clear monotonic increase in subjective duration as $\mathrm{S}$ became more bored. (Using the method of production, a lower score is equivalent to a higher subjective duration.) The results are easily significant; $\chi_{r}^{2}$ for orderings in the four sessions equals 12.00 in both tables, $p<.001$.

Finally, since the difference between the five- and tensecond estimates was in means and variances, we can compare the effect of boredom on the two by looking at the average standard scores. The last columns in Tables 2 and 3 are strikingly similar, suggesting that the two types of estimates are influenced to an almost identical extent.

Table 3. The Effect of Boredom on Ten Second Estimates

\begin{tabular}{cccccc} 
& \multicolumn{5}{c}{ Series } \\
Cue & \multicolumn{1}{c}{ I } & II & III & IV & Mean \\
B3 & -1.34 & -1.04 & -1.32 & -1.05 & -1.19 \\
B2 & -0.23 & -0.32 & -0.34 & -0.75 & -0.41 \\
B1 & 0.32 & 0.46 & 0.65 & 0.65 & 0.52 \\
0 & 0.94 & 0.59 & 0.90 & 1.15 & 0.90
\end{tabular}

Note: Each entry under series is the average (in standard scores) of three trials.

\section{Diseussion}

The data provide unusually consistent support for the hypothesis that degree of boredom is related to subjective time. An experiment with an "N" of one, of course, leaves much to be desired in terms of generalizability. It should be reiterated that this study did not seek so much to confirm the hypothesis of a relationship as it did to test the workability of a technique-hypnotic manipulation and control-in this general area of experimentation. The significant results are even more striking, therefore, when one considers that they were obtained without the use of large sample size to compensate for large amounts of random error.

The manipulation and control of boredom and other. subjective experiences by hypnotic methods promises the possibility of rigorous research on many questions concerning time estimation. Experimenters can use their intra-individual comparisons, their short intervals, etc., and yet not suffer from uncertainty and imprecision in their experimental inductions.

To be a useful scientific tool, however, hypnosis must be utilized under carefully specified conditions. For example, extreme care must be taken to phrase instructions in a way that will not bias the results, since hypnotic subjects are known to be particularly susceptible to subtle clues. The researcher wanting to try this technique would be advised to thoroughly acquaint himself with the warnings contained in the writings of Orne, Barber, Hilgard, and others. Blum $(1961,1963)$ and Geiwitz (1964) have more complete discussions of possible pitfalls and also provide examples of instruction phrasing and potential uses.

\section{Referenees}

BINDRA, D., \& WAKSBERG, HELENE. Methods and terminology in studies of time estimation. Psychol. Bull., 1956, 53, 155-159.

BLUM, G. S. A model of the mind. New York: Wiley, 1961 .

BLUM, G. S. Programming people to simulate machines. In S. S. Tomkins and S. Messick (Eds.), Computer simulation of personality. New York: Wiley, 1963.

GEIWITZ, P. J. The structure of boredom. Unpublished doctoral dissertation, Univer. of Michigan, 1964.

LOEHLIN, J. C. The influence of different activities on the apparent length of time. Psychol. Monogr., 1959, 73, No. 4 (Whole No. 474).

WEITZENHOFFER, A. M., \& HILGARD, E. R. Stanford Hypnotic Susceptibility Scale, Forms A and B. Palo Alto, Calif.: Consulting Psychologist Press, 1959. Note

1. This research was supported by the National Institute of Mental Health, grant No. 1 F1 MH-21, 603-01. The author is indebted to Dr. G.S. Blum for his helpful comments and criticisms. 